\title{
Stochastic Volatility in General Equilibrium
}

\author{
George Tauchen *
}

This Draft: June 2005

(First Circulated Draft: June 15, 2004)

\begin{abstract}
The connections between stock market volatility and returns are studied within the context of a general equilibrium framework. The framework rules out a priori any purely statistical relationship between volatility and returns by imposing uncorrelated innovations. The main model generates a two-factor structure for stock market volatility along with time-varying risk premiums on consumption and volatility risk. It also generates endogenously a dynamic leverage effect (volatility asymmetry), the sign of which depends upon the magnitudes of the risk aversion and the intertemporal elasticity of substitution parameters.
\end{abstract}

Keywords: stochastic volatility, risk aversion, leverage effect, volatility asymmetry

JEL classification: G12, C51, C52.

*Presented at the "Conference on Financial Econometrics" in honor of Rob Engle's Nobel Prize, October 2004, and the UCLA joint Finance-Econometrics workshop March 2005. This paper reflects an effort to understand better the underlying economics of stochastic volatility, risk, return, time varying risk premiums, and the volatility risk premium. I have benefitted from many helpful discussions with Ravi Bansal. Thanks also go to Ivan Shaliastovich and Kenneth Singleton for helpful comments. Author's Contact: George Tauchen, Department of Economics, Duke University, Box 90097, Durham NC 27708, E-mail george.tauchen@duke.edu 


\section{Introduction}

Observers of financial markets have long noted that the volatility of financial price movements varies stochastically. The well-established ARCH and GARCH models of Engle (1982) and Bollerslev (1986) and the plethora of descendants provide a very convenient framework for empirical modelling of volatility dynamics. A somewhat different, but essentially equivalent way to model the same phenomenon is to think in terms of the latent stochastic volatility model introduced in embryonic form by Clark (1973), extended and formalized in Taylor (1982, 1986), and studied extensively in the vast literature that follows (See Ghysels, Harvey, Renault (1996) and Shephard (2005)). Financial market empiricists now know that time varying stochastic volatility can account for much of the dynamics of short-term financial price movements.

The empirical volatility literature has proceeded largely in a reduced form statistical manner, with only minimal guidance from economic theory. The role of theory has mainly been to identify important markets and sometimes to provide informal intuitive interpretation of empirical regularities.

This paper studies stock market volatility within a self-contained general equilibrium framework. The economy is a familiar endowment economy with a preference structure assumed to be that of Epstein and Zin (1991) and Weil (1989). The paper is an extension of Bansal, Khatchatrian, and Yaron (2003), Bansal and Yaron (2004), Campbell and Hentschel (1992), and Campbell (2003). As in those papers, the loglinearization methods of Campbell and Shiller (1988) are used to derive qualitative predictions and gain further insights into the implications of the models under consideration. In this paper, however, the volatility dynamics are more complicated. The paper proceeds through a sequence of models, with each extension motivated by a desire to explore more fully the relationship between stock market returns and volatility. The models, and in particular the most general model considered in Sections 3-4 below, yield some interesting insights that can account for known characteristics of stock market volatility.

For instance, empirical researchers have long known that stock market returns and stock market volatility are negatively correlated. Black (1976) is perhaps the first to call attention to this empirical regularity and attributes it to changing financial leverage associated with equity prices changes, as further studied by Christie (1982). The asymmetric effect has thus been termed the leverage effect, and Nelson (1991) highlights its importance by formally building the asymmetry into the E-GARCH model. 
Although the term leverage effect, or simply leverage, is the common expression in the econometrics and stochastic volatility literatures, few, if any, economists are comfortable with the original explanation and believe the leverage effect has more to do with risk premiums than balance sheet leverage.

Economic explanations for the leverage effect such as French, Schwert, and Stambaugh (1987) employ intuitive traditional CAPM-type reasoning with a presumption that volatility carries a positive risk premium. A related approach (Campbell and Hentschel, 1992) uses the Merton (1973) model to connect expected returns to volatility along with a GARCH-type model for the evolution of volatility. Bekaert and Wu (2000) provide a comprehensive review of these explanations and a very convenient reduced-form setup for empirical analysis of volatility asymmetry relationships. Wu (2001) develops a self-contained equilibrium model, along with carefully executed empirical work, but the model relies on a pre-specified pricing kernel not directly connected to marginal utility. Also Wu's model permits correlations between cash flow innovations and their volatilities that provide a statistical channel for a leverage effect separate from any economic channels.

The main model developed and analyzed in Section 3-4 indicates that the existence and sign of the leverage effect depend critically on the values of two key economic parameters, the coefficient of risk aversion and the intertemporal elasticity of substitution. In the case of expected utility, these parameters are reciprocals of each other, and the model predicts no leverage effect at all in this case. Thus, the now well-established empirical finding of a negative leverage effect - which is reconfirmed in Figures 1 and Figures 2 below — strongly discredits the expected utility paradigm. Furthermore, economists generally agree that the coefficient of risk aversion exceeds unity; if so, the predicted sign of the leverage effect depends critically on the location of the intertemporal elasticity of substitution relative to unity. If this elasticity parameter exceeds unity, then the leverage effect is negative - exactly as observed in the data. On the other hand, if it is below unity, then the sign of the leverage effect is positive, in direct contrast to empirical findings. The issue of whether the intertemporal elasticity of substitution is below or above unity is contentious; Bansal and Yaron (2005) give details on the debate. Since the negative relationship has been so well documented (e.g., Bekaert and $\mathrm{Wu}, 2000$ ), the findings from reduced-form modeling of asymmetric volatility thereby have sharp consequences for an economic debate regarding the magnitude of a key utility parameter. In addition, the model can also explain the dynamic leverage effect, i.e., the pattern of serial cross correla- 
tions between stock market movements and volatility at different leads and lags as documented empirically in Litvinova (2004) and Bollerslev, Litvinova, and Tauchen (2004).

The model can also account for the empirical finding that stock market volatility appears to follow a two factor structure, with one slowly evolving component and one quickly mean reverting component. Engle and Lee (1999), Gallant, Hsu, and Tauchen (1999), and Alizadeh, Brandt, and Diebold (2002), among many others, adduce evidence on this empirical regularity. The two factor structure emerges naturally from the internal structure of the model.

Finally, the model appears useful for sorting out issues related to time varying risk prices and a volatility risk premium. A common presumption is that increased stock market volatility is associated with increased expected stock market returns. This reasoning is intuitively plausible — riskier investments should demand a higher expected return relative to cash — and a rigorous analysis is Merton (1973). Various expositions of the Merton model appear in the literature, and a convenient summary with easy to interpret log-linear approximations is in Campbell, Lo, and Mackinlay (1997, pp. 291-334). An early effort to model and detect empirically the returnvolatility relationship is Engle et al (1987), who propose the GARCH-M model for bond returns. The follow-up literature from Nelson (1991) onwards is huge, but, as is well known, the effort to detect an empirical relationship between expected stock returns and volatility has yielded weak and mixed results. Recent efforts, such as Ghysels, Santa-Clara, and Valkanov (2005) and Lundblad (2004) employ more powerful techniques to present evidence for a statistically significant positive riskreturn relationship, which has been here-to-for quite difficult to detect. However, as will be seen in Section 4, such efforts are detecting the confounding of time-varying risk premiums on consumption and volatility risk, which clouds the interpretation of the empirical evidence. Scruggs (1998), Guo and Whitelaw (2003), and Guo, Savickas, Wang, and Yang (2005) present evidence that additional factors are needed in the return-volatility equation in order to measure volatility risk reliably, and the main model below suggests the underlying variable for which these factors are likely proxies.

The rest of this paper is organized as follows: Section 2 presents the notatation and two initial models that are useful for understanding the basic structure and ideas. Section 3 sets forth the main model, and Section 4 connects the predictions from that model to the empirical stochastic volatility literature. Section 5 contains the concluding remarks. 


\section{Setup, Notation, and Two Initial Models}

\subsection{The MRS and Asset Pricing}

Let $\mathcal{M}_{t+1}$ denote the marginal rate of substitution process (MRS), also sometimes termed the stochastic discount factor (SDF), between $t$ and $t+1$, and let $R_{t+1}$ denote the gross return on an asset. The fundamental asset pricing relationship is

$$
\mathrm{E}_{t}\left(\mathcal{M}_{t+1} R_{t+1}\right)=1 .
$$

Throughout, we shall work under a conditional lognormality assumption. Let $m_{t+1}=$ $\log \left(\mathcal{M}_{t+1}\right)$, and let $r_{t+1}=\log \left(R_{t+1}\right)$ denote the geometric return on the asset. The fundamental asset pricing relationship is then

$$
\log \left[\mathrm{E}_{t}\left(e^{m_{t+1}+r_{t+1}}\right)\right]=0 .
$$

We start by working through in this section two models that illustrate the main points about time varying a risk premium on consumption versus a volatility risk premium. We then proceed to the main model in Section 3 below.

\subsection{CRR Preferences and Stochastic Volatility}

Under constant relative risk aversion (CRR) preferences $\mathcal{M}_{t+1}=\beta\left(C_{t+1} / C_{t}\right)^{-\gamma}$, where $C_{t}$ is real consumption and $\beta$ and $\gamma$ are parameters. Equivalently,

$$
m_{t+1}=\delta-\gamma g_{t+1},
$$

where $\delta=\log \beta$ and

$$
g_{t+1}=c_{t+1}-c_{t}, \quad c_{t}=\log \left(C_{t}\right),
$$

so $g_{t+1}$ is the geometric growth rate of consumption. Assume the dynamics of $g_{t+1}$ are

$$
\begin{aligned}
g_{t+1} & =\mu_{g}+\sigma_{c t} z_{c, t+1} \\
\sigma_{c, t+1}^{2} & =a_{\sigma c}+\rho_{\sigma c} \sigma_{c t}^{2}+\phi_{\sigma c} \sigma_{c t} z_{\sigma, t+1}
\end{aligned}
$$

where $\sigma_{c t}$ represents stochastic volatility in consumption that is observed by agents but not by the econometrician, and $z_{c, t+1}$ and $z_{\sigma, t+1}$ are iid $\mathrm{N}(0,1)$ random variables. The above volatility dynamics are not quite the same as those of Bansal and Yaron (2004) and Bansal, Khatchatrian, and Yaron (2003), who have a constant multiplying $z_{\sigma, t+1}$, as do and Brenner, Ou, and Zhou (2004) in their continuous time version of a setup like (4). These other papers use Gaussian volatility dynamics while (4) is 
a square-root, or CIR, type specification. There are certain consequences to the alternative specifications as discussed farther below. In simulations, of course, care is needed to include an additional reflecting barrier at a small positive number to ensure positivity of simulated $\sigma_{c, t+1}^{2}$. The above dynamics for volatility are similar to those of Bollerslev and Zhou (2003) for their continuous time assessment of the relationship between the expected stock return volatility relationship.

Let $v_{t}=\log \left(P_{t} / C_{t}\right)$ denote $\log$ of the price-dividend ratio of the asset that pays the consumption endowment $\left\{C_{t+j}\right\}_{j=1}^{\infty}$. Let

$$
r_{t+1}=\log \left(\frac{P_{t+1}+C_{t+1}}{P_{t}}\right)
$$

denote the geometric return (hereafter just called the return). The standard CampbellShiller (1988) log-linearization is

$$
r_{t+1}=k_{0}+k_{1} v_{t+1}-v_{t}+g_{t+1}
$$

where $k_{1}<1, k_{1} \approx 1$, is a positive constant. The strategy to solve models of this sort is to conjecture a solution for $v_{t}$ as a function of the state variables, use the approximation immediately above, impose the fundamental asset pricing equation, and then solve for the coefficients of the conjectured solution.

In this case we conjecture

$$
v_{t}=A_{0}+A_{\sigma} \sigma_{c t}^{2}
$$

and the solutions for $A_{0}, A_{\sigma}$ are given in Subsection 6.1 of the Appendix. From the solution one can easily derive the familiar relationship for the expected excess return

$$
\mathrm{E}_{t}\left(r_{t+1}\right)-r_{f t}=\gamma \sigma_{c t}^{2}-\frac{1}{2} \sigma_{r t}^{2}
$$

where $r_{f t}$ is the riskless rate in geometric form and $\frac{1}{2} \sigma_{r t}^{2}=\frac{1}{2} \operatorname{Var}_{t}\left(r_{t+1}\right)$ is a geometric adjustment term, also called a Jensen's Inequality adjustment (Campbell, Lo, and Mackinlay, 1997, p. 307). The risk premium is thus $\gamma \sigma_{c t}^{2}$, and, ignoring the geometric adjustment, one can write

$$
r_{t+1}-r_{f t}=\alpha+\gamma \sigma_{c t}^{2}+\epsilon_{t+1}
$$

where $\alpha$ is an intercept and $\epsilon_{t+1}$ is a heteroskedastic error term. This expression is the elusive risk-return relationship that has been sought after by Nelson (1991), Lundblad (2004), and Ghysels el al (2004), among others. 
One has to be very careful on how to interpret the risk premium in (9), however. It is actually a time-varying risk premium on consumption risk, with a variable coefficient that is attributable to the stochastic volatility; this interpretation is emphasized by Bansal and Yaron (2004) and less directly in (Campbell, Lo, and Mackinlay, 1997, p. 307). The fact that stochastic volatility generates time-varying risk premium on other factors (here consumption risk) appears first to have made formal in an econometric sense by Engle et al (1987), who use a GARCH-in-mean model to study the risk premium in bond returns.

It proves interesting to examine why (9) does not reflect a volatility risk premium. In this model, any return that depends only on the volatility innovation $z_{\sigma, t+1}$ carries no risk premium, despite the fact that the volatility innovation $z_{\sigma, t+1}$ has an impact on the return; one can easily show that

$$
r_{t+1}-\mathrm{E}_{t}\left(r_{t+1}\right)=\sigma_{c t} z_{c, t+1}+k_{1} A_{\sigma} \phi_{\sigma c} \sigma_{c t} z_{\sigma, t+1}
$$

so the volatility innovation $z_{\sigma, t+1}$ affects the return, and possibly substantially. Nonetheless, an arithmetic return that is a pure volatility bet such as

$$
R_{\sigma, t+1}=\exp \left(r_{f t}-\frac{1}{2} \varsigma_{t}^{2}+\varsigma_{t} z_{\sigma, t+1}\right)
$$

where $\varsigma_{t}$ is a constant known at time $t$, satisfies

$$
\mathrm{E}_{t}\left(R_{\sigma, t+1}\right)=R_{f t}
$$

where $R_{f t}=e^{r_{f t}}$; i.e., $R_{\sigma, t+1}$ carries no risk premium. Also, if $C\left(\sigma_{c, t+1}^{2}\right)$ is a cash flow realized at $t+1$ that only depends upon $\sigma_{c, t+1}^{2}$, then the price (present value) of that cash flow satisfies

$$
\mathrm{E}_{t}\left[\mathcal{M}_{t+1} C\left(\sigma_{c, t+1}^{2}\right)\right]=\frac{\mathrm{E}\left[C\left(\sigma_{c, t+1}^{2}\right)\right]}{R_{f t}} .
$$

There is no reward for bearing volatility risk because that risk is uncorrelated with the MRS process due to the assumption that $z_{c, t+1}$ and $z_{\sigma, t+1}$ are uncorrelated. Of course one could always generate a volatility risk premium by simply correlating $z_{c, t+1}$ and $z_{\sigma, t+1}$, but that seems ad hoc and economically unsatisfactory.

\subsection{Epstein-Zin-Weil Preferences and Stochastic Volatility}

Bansal and Yaron (2004) and Bansal, Khatchatrian, and Yaron (2003) note that Epstein-Zin-Weil preferences can actually induce an endogenous volatility risk premium. We start with a simplified version of their setups, point out some problems, and then proceed to a more general version in the next section. 
Write the log of the marginal rate of substitution as

$$
m_{t+1}=b_{m 0}+b_{m g} g_{t+1}+b_{m r} r_{t+1}
$$

and note that under Epstein-Zin-Weil preferences

$$
\begin{aligned}
& b_{m 0}=\theta \log (\delta) \\
& b_{m g}=-\theta / \psi \\
& b_{m r}=\theta-1
\end{aligned}
$$

where

$$
\theta=\frac{1-\gamma}{1-\frac{1}{\psi}}
$$

The parameter $\gamma$ is the risk aversion parameter; $\psi$ is the coefficient of intertemporal substitution, and $\delta$ the subjective discount factor. If $\theta=1$ then these preferences reduce to the CRR preferences studied above. We retain the same dynamics (4) for consumption growth and volatility. The primary differences between this setup and that of Bansal and Yaron (2004) are that the above entails square-root volatility dynamics instead of the simpler Gaussian dynamics but it excludes the long run risk factor in the consumption growth equation. That factor is excluded only for simplification to concentrate attention on the role of volatility.

The return on the consumption endowment $r_{t+1}$ that appears in the expression for the log of the marginal rate of substitution (14) has to be solved for endogenously. As before, first conjecture a solution for log price-consumption ratio

$$
v_{t}=A_{0}+A_{\sigma} \sigma_{c t}^{2}
$$

Subsection 6.2 of the Appendix contains the derivation of $A_{0}$ and $A_{\sigma}$ along with the reduced form expressions for $r_{t+1}$ and $m_{t+1}$.

From these expressions one can deduce the expression for the expected excess return

$$
\mathrm{E}_{t}\left(r_{t+1}\right)-r_{f t}=-\left(b_{m r}+b_{m g}\right) \sigma_{c t}^{2}-b_{m r} k_{1}^{2} A_{\sigma}^{2} \phi_{\sigma c}^{2} \sigma_{c t}^{2}-\frac{1}{2} \sigma_{r t}^{2}
$$

which in the case of Epstein-Zin-Weil preferences reduces to

$$
\mathrm{E}_{t}\left(r_{t+1}\right)-r_{f t}=\gamma \sigma_{c t}^{2}+(1-\theta) k_{1}^{2} A_{\sigma}^{2} \phi_{\sigma c}^{2} \sigma_{c t}^{2}-\frac{1}{2} \sigma_{r t}^{2}
$$

where again $-\frac{1}{2} \sigma_{r t}^{2}$ is the geometric adjustment term. The expected excess return

$$
\gamma \sigma_{c t}^{2}+(1-\theta) k_{1}^{2} A_{\sigma}^{2} \phi_{\sigma c}^{2} \sigma_{c t}^{2}
$$


is composed of two terms. The first term represents the familiar time varying risk premium on consumption risk, while the second represents the risk premium on volatility. The volatility risk premium is generated endogenously via the structure of the preferences, and, in fact, is absent in the CRR case where $\theta=1$. However, both risk premiums are multiples of the same stochastic process, $\sigma_{c t}^{2}$, and would thus be impossible to separately identify empirically. In the expression (20) for the expected excess return, the volatility risk premium gets confounded with the consumption risk premium. The confounding reflects the specification of stochastic volatility in (4) above. By way of contrast, in the models of Bansal and Yaron (2004) and Bansal et al (2003) the volatility risk premium gets folded into a constant term. Lettau, Ludvigson and Wachter (2004) also present a model where there is an excess return related to consumption volatility like that of (20). Their model is a stochastic volatility model where volatility is governed by a stochastic Markov regime switching variable. Like (4) above, there is a single variable - the volatility state - that governs both the location and scale of volatility, and the excess expected return is a confounding of the time varying consumption risk premium and the volatility risk premium.

\section{Main Model}

Consider the following model where consumption growth is

$$
g_{t+1}=\mu_{g}+\sigma_{c t} z_{c, t+1}
$$

as in (4), and the stochastic volatility specification is generalized to

$$
\begin{aligned}
\sigma_{c, t+1}^{2} & =a_{\sigma c}+\rho_{\sigma c} \sigma_{c t}^{2}+q_{t}^{\frac{1}{2}} z_{\sigma, t+1} \\
q_{t+1} & =a_{q}+\rho_{q} q_{t}+\phi_{q} q_{t}^{\frac{1}{2}} z_{q, t+1} .
\end{aligned}
$$

Now we allow for stochastic volatility of the volatility process via the $q_{t}$ process. This characteristic of volatility is known to be empirically important; see Chernov et al (2003) and the references therein.

The log of the marginal rate of substitution remains

$$
m_{t+1}=b_{m 0}+b_{m g} g_{t+1}+b_{m r} r_{t+1}
$$

where expressions for the coefficients are given in (15) for Epstein-Zin-Weil preferences. 
Let $v_{t}$ denote the log price dividend ratio of an asset paying the consumption endowment and $r_{t+1}$ denote the return. Conjecture a linear expression for $v_{t}$

$$
v_{t}=A_{0}+A_{\sigma} \sigma_{c t}^{2}+A_{q} q_{t}
$$

where $A_{0}, A_{\sigma}, A_{q}$ are constants whose derivation is in Subsection 6.3 of the Appendix. This subsection of the Appendix also contains the reduced form expressions for the marginal rate of substitution and the return. From these expressions one can deduce that the conditional mean excess return is

$$
\mathrm{E}_{t}\left(r_{t+1}\right)-r_{f t}=-\left[\left(b_{m r}+b_{m g}\right) \sigma_{c t}^{2}+b_{m r} k_{1}^{2}\left(A_{\sigma}^{2}+A_{q}^{2} \phi_{q}^{2}\right) q_{t}\right]-\frac{1}{2} \sigma_{r t}^{2}
$$

where $-\frac{1}{2} \sigma_{r t}^{2}=-\frac{1}{2} \operatorname{Var}_{t}\left(r_{t+1}\right)$ is the geometric adjustment term. For Epstein-Zin-Weil preferences, the conditional mean excess return reduces to

$$
\mathrm{E}_{t}\left(r_{t+1}\right)-r_{f t}=\gamma \sigma_{c t}^{2}+(1-\theta) k_{1}^{2}\left(A_{\sigma}^{2}+A_{q}^{2} \phi_{q}^{2}\right) q_{t}-\frac{1}{2} \sigma_{r t}^{2}
$$

The risk premium

$$
\gamma \sigma_{c t}^{2}+(1-\theta) k_{1}^{2}\left(A_{\sigma}^{2}+A_{q}^{2} \phi_{q}^{2}\right) q_{t}
$$

is composed of two separate terms, where the first term reflects the risk premium on consumption risk and the second the risk premium on volatility risk. The latter is a confounding of a risk premium on shocks to volatility, $z_{\sigma, t+1}$, and shocks to the volatility of volatility, $z_{q, t+1}$, but nonetheless this risk premium (or more precisely the risk price) can be separately identified from that of consumption risk. Indeed, Scruggs (1998) and Guo and Whitelaw (2003) present evidence that additional control factors are needed in the return-volatility equation in order to estimate reliably the relationship between expected return and volatility. In both cases, the additional factors include at least one interest rate variable, which is arguable a proxy for $q_{t}$ in the equation immediately above, given that the level of interest rates is associated with the turbulence of financial markets. Guo, Savickas, Wang, and Yang (2005) suggests that the value premium needs to be included, which is the likely prediction of a model like this one but with a long run risk factor as in Bansal and Yaron (2004), but has been suppressed for simplicity. In a somewhat different vein, Adrian and Rosenberg (2005) find empirical evidence that a two-factor type structure is helpful for explaining the cross-section of expected asset returns.

Interestingly, the sign of the volatility risk premium depends critically on the sign of $1-\theta$, where $\theta$ is defined in (16). Most economists would probably agree that $\gamma>1$, 
i.e., the agent is more risk averse than a $\log$ investor. If $\gamma>1$, then the sign of

$$
1-\theta=\frac{\gamma-\frac{1}{\psi}}{1-\frac{1}{\psi}}
$$

depends upon $\psi$. A sufficient condition for a positive volatility risk premium is $\psi>1$, which Bansal and Yaron (2004) argue is the most reasonable region for $\psi$. On the other hand, a number of economists (see Campbell and Koo, 1997, and the references therein) argue that $\psi<1$. If so, then it would take rather small values of $\psi$ to generate a positive risk premium on volatility since

$$
\begin{aligned}
\psi<\frac{1}{\gamma} & \Rightarrow 1-\theta>0 \\
\frac{1}{\gamma}<\psi<1 & \Rightarrow 1-\theta<0 .
\end{aligned}
$$




\section{Stock Price and Volatility Dynamics}

Much of the stochastic volatility literature examines the log capital return process

$$
\Delta p_{t}=\log \left(P_{t}\right)-\log \left(P_{t-1}\right)
$$

instead of the total return process, $r_{t}$, which includes the dividend yield. In this section we shall study the dynamics of the volatility of $\Delta p_{t}$ implied by the general stochastic volatility model of Section 3; the conclusions are essentially the same for either process, because the capital gain return tends to dominate the total return.

The reduced form expression for the $\Delta p_{t}$ process is derived in the Subsection 6.3 of the Appendix and takes the form

$$
\begin{aligned}
\Delta p_{t}= & b_{p 0}+A_{\sigma}\left(\rho_{\sigma c}-1\right) \sigma_{c, t-1}^{2}+A_{q}\left(\rho_{q}-1\right) q_{t-1}+ \\
& \sigma_{c, t-1} z_{c, t}+A_{\sigma} q_{t-1}^{\frac{1}{2}} z_{\sigma, t}+A_{q} \phi_{q} q_{t-1}^{\frac{1}{2}} z_{q, t}
\end{aligned}
$$

where $b_{p 0}$ is a constant and the other parameters are defined in Subsection 6.3 of the Appendix. Note that from (85) $A_{\sigma}$ is of the form

$$
A_{\sigma}=\frac{1}{\theta} h_{\sigma}, \quad h_{\sigma}>0
$$

and from (86) $A_{q}$ is of the form

$$
A_{q}=\frac{1}{\theta} h_{q}, \quad h_{q}>0
$$

and so the signs of $A_{\sigma}$ and $A_{q}$ are same as those of $\theta$ defined in (16) above.

We consider first the dynamic relationship between $\Delta p_{t}$ and the consumption volatility process $\sigma_{c t}^{2}$. It follows from the expression (32) and the dynamics (22) that

$$
\begin{aligned}
& \operatorname{Cov}\left(\Delta p_{t}, \sigma_{\sigma c, t-j}^{2}\right)=A_{\sigma}\left(\rho_{\sigma}-1\right) \mathrm{E}\left(\sigma_{c, t-1}^{4}\right) \rho_{\sigma c}^{j-1}, \quad j=1,2, \ldots, \infty \\
& \operatorname{Cov}\left(\Delta p_{t}, \sigma_{c t}^{2}\right)=\rho_{q} A_{\sigma}\left(\rho_{\sigma c}-1\right) \mathrm{E}\left(\sigma_{c, t-1}^{4}\right)+A_{\sigma} \mathrm{E}\left(q_{t-1}\right) \\
& \operatorname{Cov}\left(\Delta p_{t}, \sigma_{c \sigma, t+j}^{2}\right)=A_{\sigma}\left(\rho_{\sigma}-1\right) \mathrm{E}\left(\sigma_{c, t-1}^{4}\right) \rho_{\sigma c}^{j}, \quad j=1,2, \ldots, \infty
\end{aligned}
$$

The serial cross covariances $\operatorname{Cov}\left(\Delta p_{t}, \sigma_{c, t+j}^{2}\right)$ for $j \neq 0$ are proportional to the autocovariance function of the $\sigma_{c t}^{2}$ process. The sign will be negative if $\theta<0$, as would be the case if both $\gamma$ and $\psi$ exceed unity. Thus, in this case a market price decline would signal increased future expected consumption volatility, a result analogous to that of Bansal, Khatchatrian, and Yaron (2003) who study the covariance between the log price dividend ratio, $v_{t}$, and subsequent consumption volatility $\sigma_{c, t+j}, j>0$. 
Interestingly, the sign of the contemporaneous covariance $\operatorname{Cov}\left(\sigma_{c t}^{2}, \Delta p_{t}\right)$ is ambiguous because it is the sum of terms of opposite signs.

To tie the theory to the stochastic volatility literature, the most interesting series is the one-step conditional variance process defined as

$$
\sigma_{p t}^{2} \equiv \operatorname{Var}_{t}\left(\Delta p_{t+1}\right)=\sigma_{c t}^{2}+\left(A_{\sigma}^{2}+A_{q}^{2} \phi_{q}^{2}\right) q_{t}
$$

From (36) it is immediately seen that conditional volatility follows a two-factor structure where it is the superposition of two autoregressive processes. This theoretical representation of volatility corresponds exactly to the two-factor structure developed empirically by Engle and Lee (1999), Gallant, Hsu, and Tauchen (1999), Barndorff-Nielsen and Shephard (2001, and additional papers at www.levyprocess.org), Alizadeh, Brandt, and, Diebold (2002) among others. The typical structure identified empirically contains one factor that is extremely persistent and another that is strongly mean reverting and nearly serially uncorrelated. In $(36), \sigma_{c t}^{2}$ is a likely candidate for the persistent factor while $q_{t}$ is likely the strongly mean reverting factor. Scruggs (1998) and Guo and Whitelaw (2003) present evidence that additional factor(s) are needed in the return-volatility equation in order to empirically measure volatility risk reliably. These factors are variables that tend to be high when financial volatility is high. Their findings are appear completely consistent with Equation (36), which suggests that these factors should be related to $q_{t}$, the volatility of volatility.

The contemporaneous leverage effect pertains to the correlation between the conditional volatility process $\sigma_{p t}^{2}$ and the capital return process $\Delta p_{t}$. An easily computed conditional moment is

$$
\operatorname{Cov}_{t-1}\left(\Delta p_{t}, \sigma_{p t}^{2}\right)=A_{\sigma} q_{t-1}+A_{q}\left(A_{\sigma}^{2}+A_{q}^{2} \phi^{2}\right) q_{t-1}
$$

One sees immediately from these covariances along with with (33), (34), and (16) the role that the utility function parameters $\gamma$ and $\psi$ play in determining the sign of the leverage effect. The covariances are negative under the parameter values utilized by Bansal and Yaron (2004).

We now consider the dynamic leverage effect. Some direct empirical evidence is seen in Figure 1, which shows the correlations between $\Delta p$ as proxied by the logarithmic return on S\&P 100 Index and leads and lags of the VIX volatility Index, daily, 1990-2004. The VIX index is designed to reflect the implied volatility on S\&P 100 Index options with one month to expiration. Evidently, a large price increase is associated with a contemporaneous drop in volatility which then slowly dies away. 
Figure 2 shows the same correlations except computed using monthly averages. The pattern remains quite apparent at the monthly frequency. Both figures are consistent with the evidence adduced in Litvinova (2004) and Bollerslev, Litvinova, and Tauchen (2004) using very high frequency data.

In order to compare the predictions from the model to the observed pattern, we need to compute analogous correlations under the model. Convenient analytical approximate results involving moments of $\sigma_{p t}^{2}$ and cross moments with other series appear to be out of reach. Instead, simulation is used to compute unconditional correlations of interest. Given a set of parameter values, the model of Section 3 is simulated for 10000 periods and population moments implied by the model are computed via Monte Carlo. Following the recommendation of Campbell and Koo (1997), the orthogonality conditions of the Euler equation error were checked and found to be negligible.

The correlations of interest are computed for two sets of parameter values, labelled Cases A and B in Table 1, which are based on Campbell and Koo (1997) and Bansal, Gallant, and Tauchen (2004). The only difference between the two cases is that the elasticity of substitution $\psi=1.50$ in $\mathrm{A}$ and $\psi=0.50$ in $\mathrm{B}$. The risk aversion parameter $\gamma$ is the same in both cases. The other values of the parameters would be reasonable for a model operating in monthly time. The model could not be expected to fit actual data because it lacks the long run risk component in consumption growth of Bansal and Yaron (2004), which is left out only for simplicity. Figure 3 shows the autocorrelation function of stock market volatility $\sigma_{p t}^{2}$ for the two sets parameter settings. The persistence of volatility is completely consistent with all empirical findings, and comparison across cases indicates that the value of the elasticity of substitution $\psi$ has little effect on volatility persistence.

Figure 4 shows predicted dynamic leverage correlations between $\Delta p_{t}$ and leads and lags of $\sigma_{p t}^{2}$. In the upper panel, where $\psi=1.50$, the contemporaneous leverage effect is a negative and it fades away over time, which is completely consistent with Figures 1 and 2. In the bottom panel, where $\psi=0.50$, the leverage effect is positive, which is completely counter factual. Interestingly, and somewhat surprisingly, the observed negative dynamic leverage effect is fairly compelling evidence for an intertemporal elasticity of substitution above unity. 


\section{Conclusion}

The characteristics of the relationships between stock market volatility and stock market returns are examined within the context of a general equilibrium framework. The framework only permits connections between volatility and returns that arise through the internal economic structure of the model. All innovations are presumed uncorrelated, thereby ruling out connections that could arise via separate statistical channels. The most general model generates a two-factor structure for volatility along with time-varying risk premiums on consumption and volatility risk. It also generates endogenously a dynamic leverage effect, the sign of which depends upon the magnitudes of the risk aversion $(\gamma)$ and intertemporal elasticity of substitution $(\psi)$ parameters. In the case of expected utility where $\gamma=1 / \psi$, the leverage effect is absent, which suggest a strong connection between non-expected utility preferences and the leverage effect. The magnitude of $\psi$ relative to unity is an issue of debate in the financial economics literature. Interestingly, if $\gamma>1$, as is commonly presumed, then the observed negative leverage effect necessarily implies $\psi>1$, so the well documented finding of negative leverage has bearing on this economic debate. 


\section{Appendix: Details of the Derivations \\ 6.1 Solution for the Model with CRR Preferences in Subsec- tion 2.2}

From the approximation $r_{t+1}=k_{0}+k_{1} v_{t+1}-v_{t}+g_{t+1}$ and the presumed dynamics for $g_{t+1}$ and $\sigma_{c, t+1}^{2}$ it follows that

$$
\begin{aligned}
r_{t+1}= & k_{0}+\left(k_{1}-1\right) A_{0}+k_{1} A_{\sigma} a_{\sigma c}+\mu_{c}+A_{\sigma}\left(k_{1} \rho_{\sigma c}-1\right) \sigma_{c t}^{2}+ \\
& k_{1} \phi_{\sigma c} A_{\sigma} \sigma_{c t} z_{\sigma, t+1}+\sigma_{c t} z_{c, t+1}
\end{aligned}
$$

and

$$
m_{t+1}=\delta-\gamma \mu_{c}-\gamma \sigma_{c t} z_{c, t+1}
$$

Thus

$$
\begin{gathered}
\mathrm{E}_{t}\left(e^{r_{t+1}+m_{t+1}}\right)=1 \Rightarrow \\
\mathrm{E}_{t}\left(r_{t+1}+m_{t+1}\right)+\frac{1}{2} \operatorname{Var}_{t}\left(r_{t+1}+m_{t+1}\right)=0 .
\end{gathered}
$$

Computing the conditional first two moments and setting the above to zero gives

$$
\begin{aligned}
& k_{0}+\left(k_{1}-1\right) A_{0}+k_{1} A_{\sigma} a_{\sigma c}+\delta+(1-\gamma) \mu_{c}+ \\
& {\left[A_{\sigma}\left(k_{1} \rho_{\sigma c}-1\right)+\frac{1}{2} k_{1}^{2} \phi_{\sigma c}^{2} A_{\sigma}^{2}+\frac{1}{2}(1-\gamma)^{2}\right] \sigma_{c t}^{2}=0 .}
\end{aligned}
$$

This can hold for all values of $\sigma_{c t}^{2}$ only if

$$
A_{0}=\frac{k_{0}+k_{1} A_{\sigma} a_{\sigma c}+\delta+(1-\gamma) \mu_{c}}{1-k_{1}}
$$

where $A_{\sigma}$ is a solution to the quadratic

$$
(1-\gamma)^{2}+2\left(k_{1} \rho_{\sigma c}-1\right) A_{\sigma}+k_{1}^{2} \phi_{\sigma c}^{2} A_{\sigma}^{2}=0
$$

There are two roots

$$
A_{\sigma}^{+,-}=\frac{1-k_{1} \rho_{\sigma c} \pm \sqrt{\left(1-k_{1} \rho_{\sigma c}\right)^{2}-(1-\gamma)^{2} k_{1}^{2} \phi_{\sigma c}^{2}}}{k_{1}^{2} \phi_{\sigma c}^{2}}
$$

which are real so long as $\phi_{\sigma c}^{2}$ is sufficiently small. The root $A_{\sigma}^{+}$has the unappealing property that

$$
\lim _{\phi_{\sigma c} \rightarrow 0} A_{\sigma}^{+} \phi_{\sigma c}^{2} \neq 0
$$

which would mean the impact of $\sigma_{c t}$ would grow without bound as stochastic volatility becomes unimportant. Thus we take $A_{\sigma}^{-}$as the economically meaningful root and set

$$
A_{\sigma}=\frac{1-k_{1} \rho_{\sigma c}-\sqrt{\left(1-k_{1} \rho_{\sigma c}\right)^{2}-(1-\gamma)^{2} k_{1}^{2} \phi_{\sigma c}^{2}}}{k_{1}^{2} \phi_{\sigma c}^{2}}
$$




\subsection{Solution for Model with EZW Preferences in Subsec- tion 2.3}

From the approximation $r_{t+1}=k_{0}+k_{1} v_{t+1}-v_{t}+g_{t+1}$ and the presumed dynamics for $g_{t+1}$ and $\sigma_{c, t+1}^{2}$ it follows that

$$
\begin{aligned}
r_{t+1}= & k_{0}+\left(k_{1}-1\right) A_{0}+k_{1} A_{\sigma} a_{\sigma c}+\mu_{c}+A_{\sigma}\left(k_{1} \rho_{\sigma c}-1\right) \sigma_{c t}^{2}+ \\
& k_{1} \phi_{\sigma c} A_{\sigma} \sigma_{c t} z_{\sigma, t+1}+\sigma_{c t} z_{c, t+1}
\end{aligned}
$$

with

$$
m_{t+1}=b_{m 0}+b_{m g} g_{t+1}+b_{m r} r_{t+1}
$$

Then

$$
\begin{aligned}
m_{t+1}= & b_{m 0}+b_{m g} \mu_{c}+ \\
& b_{m r}\left[k_{0}+\left(k_{1}-1\right) A_{0}+k_{1} A_{\sigma} a_{\sigma c}+\mu_{c}+A_{\sigma}\left(k_{1} \rho_{\sigma c}-1\right) \sigma_{c t}^{2}\right]+ \\
& b_{m r} k_{1} \phi_{\sigma c} A_{\sigma} \sigma_{c t} z_{\sigma, t+1}+\left(b_{m r}+b_{m g}\right) \sigma_{c t} z_{c, t+1}
\end{aligned}
$$

Thus

$$
\begin{aligned}
r_{t+1}+m_{t+1}= & \left(1+b_{m r}\right)\left[k_{0}+\left(k_{1}-1\right) A_{0}+k_{1} A_{\sigma} a_{\sigma c}\right]+ \\
& \left(1+b_{m r}+b_{m g}\right) \mu_{c}+b_{m 0}+\left(1+b_{m r}\right)\left[A_{\sigma}\left(k_{1} \rho_{\sigma c}-1\right)\right] \sigma_{c t}^{2}+ \\
& \left(1+b_{m r}\right) k_{1} \phi_{\sigma c} A_{\sigma} \sigma_{c t} z_{\sigma, t+1}+\left(1+b_{m r}+b_{m g}\right) \sigma_{c t} z_{c, t+1}
\end{aligned}
$$

and

$$
\begin{gathered}
\mathrm{E}_{t}\left(r_{t+1}+m_{t+1}\right)=\left(1+b_{m r}\right)\left[k_{0}+\left(k_{1}-1\right) A_{0}+A_{\sigma} k_{1} a_{\sigma c}\right]+ \\
\left(1+b_{m r}+b_{m g}\right) \mu_{c}+b_{m 0}+\left(1+b_{m r}\right)\left[A_{\sigma}\left(k_{1} \rho_{\sigma c}-1\right)\right] \sigma_{c t}^{2}, \\
\operatorname{Var}_{t}\left(r_{t+1}+m_{t+1}\right)=\left[\left(1+b_{m r}\right)^{2} k_{1}^{2} \phi_{\sigma c}^{2} A_{\sigma}^{2}+\left(1+b_{m r}+b_{m g}\right)^{2}\right] \sigma_{c t}^{2} .
\end{gathered}
$$

Imposing

$$
\mathrm{E}_{t}\left(r_{t+1}+m_{t+1}\right)+\frac{1}{2} \operatorname{Var}_{t}\left(r_{t+1}+m_{t+1}\right)=0
$$

and equating to zero the constant and coefficient of $\sigma_{c t}^{2}$ gives the equations

$$
\begin{aligned}
0= & \left(1+b_{m r}\right)\left[k_{0}+\left(k_{1}-1\right) A_{0}+k_{1} A_{\sigma} a_{\sigma c}\right]+ \\
& \left(1+b_{m r}+b_{m g}\right) \mu_{c}+b_{m 0} \\
0= & \left(1+b_{m r}\right)\left(k_{1} \rho_{\sigma c}-1\right) A_{\sigma}+ \\
& \frac{1}{2}\left[\left(1+b_{m r}\right)^{2} k_{1}^{2} \phi_{\sigma c}^{2} A_{\sigma}^{2}+\left(1+b_{m r}+b_{m g}\right)^{2}\right] .
\end{aligned}
$$


Thus

$$
A_{0}=\frac{k_{0}+k_{1} A_{\sigma} a_{\sigma c}}{\left(1-k_{1}\right)}+\frac{\left(1+b_{m r}+b_{m g}\right) \mu_{c}+b_{m 0}}{\left(1+b_{m r}\right)\left(1-k_{1}\right)}
$$

where $A_{\sigma}$ is the solution of the quadratic

$$
\left(1+b_{m r}+b_{m g}\right)^{2}+2\left(1+b_{m r}\right)\left(k_{1} \rho_{\sigma c}-1\right) A_{\sigma}+\left(1+b_{m r}\right)^{2} k_{1}^{2} \phi_{\sigma c}^{2} A_{\sigma}^{2}=0
$$

There are two roots

$$
A_{\sigma}^{+,-}=\frac{1-k_{1} \rho_{\sigma c} \pm \sqrt{\left(1-k_{1} \rho_{\sigma c}\right)^{2}-\left(1+b_{m r}+b_{m g}\right)^{2} k_{1}^{2} \phi_{\sigma c}^{2}}}{\left(1+b_{m r}\right) k_{1}^{2} \phi_{\sigma c}^{2}}
$$

The root $A_{\sigma}^{+}$has the unappealing property that

$$
\lim _{\phi_{\sigma c}^{2} \rightarrow 0} \phi_{\sigma c}^{2} A_{\sigma}^{+} \neq 0
$$

so we take $A_{\sigma}^{-}$as the economically meaningful root and set

$$
A_{\sigma}=\frac{1-k_{1} \rho_{\sigma c}-\sqrt{\left(1-k_{1} \rho_{\sigma c}\right)^{2}-\left(1+b_{m r}+b_{m g}\right)^{2} k_{1}^{2} \phi_{\sigma c}^{2}}}{\left(1+b_{m r}\right) k_{1}^{2} \phi_{\sigma c}^{2}}
$$

In the case of Epstein-Zin-Weil preferences the coefficients are

$$
\begin{gathered}
A_{0}=\frac{k_{0}+k_{1} A_{\sigma} a_{\sigma c}}{\left(1-k_{1}\right)}+\frac{(1-\gamma) \mu_{c}+\theta \log (\delta)}{\theta\left(1-k_{1}\right)} \\
A_{\sigma}=\frac{1-k_{1} \rho_{\sigma c}-\sqrt{\left(1-k_{1} \rho_{\sigma c}\right)^{2}-(1-\gamma)^{2} k_{1}^{2} \phi_{\sigma c}^{2}}}{\theta k_{1}^{2} \phi_{\sigma c}^{2}}
\end{gathered}
$$

It is useful to record the reduced form expression for $m_{t+1}, r_{t+1}$ :

$$
\begin{gathered}
m_{t+1}=b_{m 0}^{*}+b_{m r} A_{\sigma}\left(k_{1} \rho_{\sigma c}-1\right) \sigma_{c t}^{2}+\left(b_{m r}+b_{m g}\right) \sigma_{c t} z_{c, t+1}+b_{m r} k_{1} A_{\sigma} \phi_{\sigma c} \sigma_{c t} z_{\sigma, t+1} \\
r_{t+1}=b_{r 0}+A_{\sigma}\left(k_{1} \rho_{\sigma c}-1\right) \sigma_{c t}^{2}+\sigma_{c t} z_{c, t+1}+k_{1} A_{\sigma} \phi_{\sigma c} \sigma_{c t} z_{\sigma, t+1}
\end{gathered}
$$

where $b_{m 0}^{*}$ and $b_{r 0}$ are readily determined constants. In the case of Epstein-Zin-Weil preferences the reduced form expressions are

$$
\begin{aligned}
m_{t+1}= & b_{m 0}^{*}+(\theta-1) A_{\sigma}\left(k_{1} \rho_{\sigma c}-1\right) \sigma_{c t}^{2}- \\
& \gamma \sigma_{c t} z_{c, t+1}+(\theta-1) k_{1} A_{\sigma} \phi_{\sigma c} \sigma_{c t} z_{\sigma, t+1} \\
r_{t+1}= & b_{r 0}+A_{\sigma}\left(k_{1} \rho_{\sigma c}-1\right) \sigma_{c t}^{2}+\sigma_{c t} z_{c, t+1}+k_{1} A_{\sigma} \phi_{\sigma c} \sigma_{c t} z_{\sigma, t+1}
\end{aligned}
$$




\subsection{Solution for the Model with EZW Preferences and Gen- eral Stochastic Volatility in Section 3}

The steps to find the solution start with

$$
\begin{aligned}
r_{t+1}= & k_{0}+\left(k_{1}-1\right) A_{0}+A_{\sigma}\left(k_{1} \sigma_{c, t+1}^{2}-\sigma_{c t}^{2}\right)+ \\
& A_{q}\left(k_{1} q_{t+1}-q_{t}\right)+g_{t+1} .
\end{aligned}
$$

Thus

$$
\begin{aligned}
m_{t+1}+r_{t+1}= & b_{m 0}+\left(1+b_{m r}\right)\left[k_{0}+\left(k_{1}-1\right) A_{0}\right]+\left(1+b_{m g}+b_{m r}\right) g_{t+1}+ \\
& \left(1+b_{m r}\right)\left[A_{\sigma}\left(k_{1} \sigma_{c, t+1}^{2}-\sigma_{c t}^{2}\right)+A_{q}\left(k_{1} q_{t+1}-q_{t}\right)\right]
\end{aligned}
$$

and so

$$
\begin{aligned}
\mathrm{E}_{t}\left(m_{t+1}+r_{t+1}\right)= & b_{m 0}+\left(1+b_{m r}\right)\left[k_{0}+\left(k_{1}-1\right) A_{0}\right]+\left(1+b_{m g}+b_{m r}\right) \mu_{g}+ \\
& \left(1+b_{m r}\right) k_{1}\left[A_{\sigma} a_{\sigma c}+A_{q} a_{q}\right]+ \\
& \left(1+b_{m r}\right)\left[A_{\sigma}\left(k_{1} \rho_{\sigma c}-1\right) \sigma_{c t}^{2}+A_{q}\left(k_{1} \rho_{q}-1\right) q_{t}\right]
\end{aligned}
$$

and

$$
\begin{aligned}
\operatorname{Var}_{t}\left(m_{t+1}+r_{t+1}\right)= & \operatorname{Var}_{t}\left[\left(1+b_{m g}+b_{m r}\right) g_{t+1}\right]+ \\
& \operatorname{Var}_{t}\left[\left(1+b_{m r}\right)\left(A_{\sigma} k_{1} \sigma_{c, t+1}^{2}+A_{q} k_{1} q_{t+1}\right)\right]
\end{aligned}
$$

This can be expressed as

$$
\begin{aligned}
\operatorname{Var}_{t}\left(m_{t+1}+r_{t+1}\right)= & \left(1+b_{m g}+b_{m r}\right)^{2} \sigma_{c t}^{2}+ \\
& \left(1+b_{m r}\right)^{2}\left(A_{\sigma}^{2} k_{1}^{2} q_{t}+A_{q}^{2} k_{1}^{2} \phi_{q}^{2} q_{t}\right)
\end{aligned}
$$

The asset pricing equation is

$$
0=\mathrm{E}_{t}\left(m_{t+1}+r_{t+1}\right)+\frac{1}{2} \operatorname{Var}_{t}\left(m_{t+1}+r_{t+1}\right)
$$

Setting to zero the constant term yields

$$
A_{0}=\frac{b_{m 0}+\left(1+b_{m r}\right)\left[k_{0}+k_{1}\left(A_{\sigma} a_{\sigma c}+A_{q} a_{q}\right)\right]+\left(1+b_{m g}+b_{m r}\right) \mu_{c}}{\left(1+b_{m r}\right)\left(1-k_{1}\right)} .
$$

The term for $\sigma_{c t}^{2}$ is

$$
\left(1+b_{m r}\right)\left(k_{1} \rho_{\sigma c}-1\right) A_{\sigma} \sigma_{c t}^{2}+\frac{1}{2}\left(1+b_{m g}+b_{m r}\right)^{2} \sigma_{c t}^{2}
$$

and setting it to zero gives

$$
A_{\sigma}=\frac{\frac{1}{2}\left(1+b_{m g}+b_{m r}\right)^{2}}{\left(1+b_{m r}\right)\left(1-k_{1} \rho_{\sigma c}\right)} .
$$


The term for $q_{t}$ is

$$
\left(1+b_{m r}\right)\left(k_{1} \rho_{q}-1\right) A_{q} q_{t}+\frac{1}{2}\left(1+b_{m r}\right)^{2}\left(A_{\sigma}^{2} k_{1}^{2} q_{t}+A_{q}^{2} k_{1}^{2} \phi_{q}^{2} q_{t}\right) .
$$

and setting it to zero gives a quadratic in $A_{q}$ :

$$
\left(1+b_{m r}\right) A_{\sigma}^{2} k_{1}^{2}+2\left(k_{1} \rho_{q}-1\right) A_{q}+\left(1+b_{m r}\right) k_{1}^{2} \phi_{q}^{2} A_{q}^{2}=0
$$

There are two real solutions

$$
A_{q}^{+}, A_{q}^{-}=\frac{1-k_{1} \rho_{q} \pm \sqrt{\left(1-k_{1} \rho_{q}\right)^{2}-\left(1+b_{m r}\right)^{2} k_{1}^{4} \phi_{q}^{2} A_{\sigma}^{2}}}{\left(1+b_{m r}\right) k_{1}^{2} \phi_{q}^{2}}
$$

so long as

$$
\phi_{q}^{2} \leq \frac{\left(1-k_{1} \rho_{q}\right)^{2}}{\left(1+b_{m r}\right)^{2} k_{1}^{4} A_{\sigma}^{2}}
$$

Note that

$$
\lim _{\phi_{q} \rightarrow 0} \phi_{q}^{2} A_{q}^{+} \neq 0
$$

which is economically unappealing, so we take the other root and set

$$
A_{q}=\frac{1-k_{1} \rho_{q}-\sqrt{\left(1-k_{1} \rho_{q}\right)^{2}-\left(1+b_{m r}\right)^{2} k_{1}^{4} \phi_{q}^{2} A_{\sigma}^{2}}}{\left(1+b_{m r}\right) k_{1}^{2} \phi_{q}^{2}} .
$$

The solution for the log price dividend ratio is thus

$$
v_{t}=A_{0}+A_{\sigma} \sigma_{c t}^{2}+A_{q} q_{t}
$$

where expressions for $A_{0}, A_{\sigma}, A_{q}$ are given immediately above. Under Epstein-ZinWeil preferences the coefficients are

$$
A_{0}=\frac{\theta\left[\log (\delta)+k_{0}+k_{1}\left(A_{\sigma} a_{\sigma c}+A_{q} a_{q}\right)\right]+(1-\gamma) \mu_{c}}{\theta\left(1-k_{1}\right)}
$$

or

$$
A_{0}=\frac{\log (\delta)+k_{0}+k_{1}\left(A_{\sigma} a_{\sigma c}+A_{q} a_{q}\right)}{1-k_{1}}+\frac{(1-\gamma) \mu_{c}}{\theta\left(1-k_{1}\right)}
$$

and

$$
A^{A_{\sigma}=\frac{\frac{1}{2}(1-\gamma)^{2}}{\theta\left(1-k_{1} \rho_{\sigma c}\right)}}
$$


The reduced form expressions for the MRS, the return, and the price change, are derived as follows. Start with

$$
\begin{gathered}
m_{t+1}=b_{m 0}+b_{m g} g_{t+1}+b_{m r} r_{t+1} \\
m_{t+1}=b_{m 0}+b_{m g} \mu_{c}+b_{m g} \sigma_{c t} z_{c, t+1}+b_{m r}\left(k_{0}+k_{1} v_{t+1}-v_{t}+g_{t+1}\right) .
\end{gathered}
$$

Hence

$$
\begin{aligned}
m_{t+1}= & b_{m 0}^{*}+b_{m r} A_{\sigma}\left(k_{1} \rho_{\sigma c}-1\right) \sigma_{c t}^{2}+b_{m r} A_{q}\left(k_{1} \rho_{q}-1\right) q_{t}+ \\
& \left(b_{m g}+b_{m r}\right) \sigma_{c t} z_{c, t+1}+b_{m r} k_{1} A_{\sigma} q_{t}^{\frac{1}{2}} z_{\sigma, t+1}+b_{m r} k_{1} A_{q} \phi_{q} q_{t}^{\frac{1}{2}} z_{q, t+1}
\end{aligned}
$$

where

$$
\begin{aligned}
b_{m 0}^{*}= & b_{m 0}+\left(b_{m g}+b_{m r}\right) \mu_{c}+b_{m r}\left[k_{0}+k_{1}\left(A_{\sigma} a_{\sigma c}+A_{q} a_{q}\right)\right]+ \\
& b_{m r}\left(k_{1}-1\right) A_{0}
\end{aligned}
$$

Under Epstein-Zin-Weil preferences the solution for the MRS is

$$
\begin{aligned}
m_{t+1}= & b_{m 0}^{*}+(\theta-1) A_{\sigma}\left(k_{1} \rho_{\sigma c}-1\right) \sigma_{c t}^{2}+(\theta-1) A_{q}\left(k_{1} \rho_{q}-1\right) q_{t}+ \\
& -\gamma \sigma_{c t} z_{c, t+1}+(\theta-1) k_{1} A_{\sigma} q_{t}^{\frac{1}{2}} z_{\sigma, t+1}+(\theta-1) k_{1} A_{q} \phi_{q} q_{t}^{\frac{1}{2}} z_{q, t+1}
\end{aligned}
$$

with

$$
\begin{aligned}
b_{m 0}^{*}= & \theta \log (\delta)-\gamma \mu_{g}+(\theta-1)\left[k_{0}+k_{1}\left(A_{\sigma} a_{\sigma c}+A_{q} a_{q}\right)\right]+ \\
& (\theta-1)\left(k_{1}-1\right) A_{0}
\end{aligned}
$$

To obtain the reduced form expressions for the return start with

$$
\begin{gathered}
r_{t+1}=k_{0}+k_{1} v_{t+1}-v_{t}+g_{t+1} \\
r_{t+1}=k_{0}+k_{1}\left(A_{0}+A_{\sigma} \sigma_{c, t+1}^{2}+A_{q} q_{t+1}\right)-\left(A_{0}+A_{\sigma} \sigma_{c t}^{2}+A_{q} q_{t}\right)+g_{t+1}
\end{gathered}
$$

which gives

$$
\begin{aligned}
r_{t+1}= & b_{r 0}+A_{\sigma}\left(k_{1} \rho_{\sigma c}-1\right) \sigma_{c t}^{2}+A_{q}\left(k_{1} \rho_{q}-1\right) q_{t}+ \\
& \sigma_{c t} z_{c, t+1}+k_{1} A_{\sigma} q_{t}^{\frac{1}{2}} z_{\sigma, t+1}+k_{1} A_{q} \phi_{q} q_{t}^{\frac{1}{2}} z_{q, t+1}
\end{aligned}
$$

where

$$
b_{r 0}=\mu_{g}+k_{0}+\left(k_{1}-1\right) A_{0}+k_{1}\left(A_{\sigma} a_{\sigma c}+A_{q} a_{q}\right)
$$

For the price change start with

$$
\Delta p_{t+1}=p_{t+1}-p_{t}=v_{t+1}-v_{t}+g_{t+1}
$$


which leads to

$$
\begin{aligned}
\Delta p_{t+1}= & b_{p 0}+A_{\sigma}\left(\rho_{\sigma c}-1\right) \sigma_{c t}^{2}+A_{q}\left(\rho_{q}-1\right) q_{t}+ \\
& \sigma_{c t} z_{c, t+1}+A_{\sigma} q_{t}^{\frac{1}{2}} z_{\sigma, t+1}+A_{q} \phi_{q} q_{t}^{\frac{1}{2}} z_{q, t+1}
\end{aligned}
$$

where

$$
b_{p 0}=\mu_{c}+A_{\sigma} a_{\sigma c}+A_{q} a_{q}
$$

The riskless rate, $r_{f t}$, is the solution to

$$
-r_{f t}=\mathrm{E}_{t}\left(m_{t+1}\right)+\frac{1}{2} \operatorname{Var}_{t}\left(m_{t+1}\right)
$$

which works out to

$$
\begin{aligned}
-r_{f t} & =b_{m 0}^{*}-(1-\theta)\left[A_{\sigma}\left(k_{1} \rho_{\sigma c}-1\right) \sigma_{c t}^{2}+A_{q}\left(k_{1} \rho_{q}-1\right) q_{t}\right]+ \\
& =\frac{1}{2} \gamma^{2} \sigma_{c t}^{2}+\frac{1}{2}(\theta-1)^{2} k_{1}^{2}\left(A_{\sigma}^{2}+\phi_{q}^{2} A_{q}^{2}\right) q_{t} .
\end{aligned}
$$


7 Tables and Figures 
Table 1: Parameter Settings Cases A and B

\begin{tabular}{rrr}
\hline Parameter & Case A & Case B \\
& & \\
$a_{\sigma c}$ & $0.10 \mathrm{e}-06$ & $0.10 \mathrm{e}-06$ \\
$\rho_{\sigma c}$ & 0.98 & 0.98 \\
$a_{q}$ & $0.20 \mathrm{e}-06$ & $0.20 \mathrm{e}-06$ \\
$\rho_{q}$ & 0.20 & 0.20 \\
$\phi_{q}$ & $0.10 \mathrm{e}-06$ & $0.10 \mathrm{e}-06$ \\
$\delta$ & 0.9949 & 0.9949 \\
$\gamma$ & 8.00 & 8.00 \\
$\psi$ & 1.50 & 0.50 \\
$\psi$ & & \\
$\mu_{c}$ & $0.163 \mathrm{e}-02$ & $0.163 \mathrm{e}-02$ \\
\hline \hline
\end{tabular}




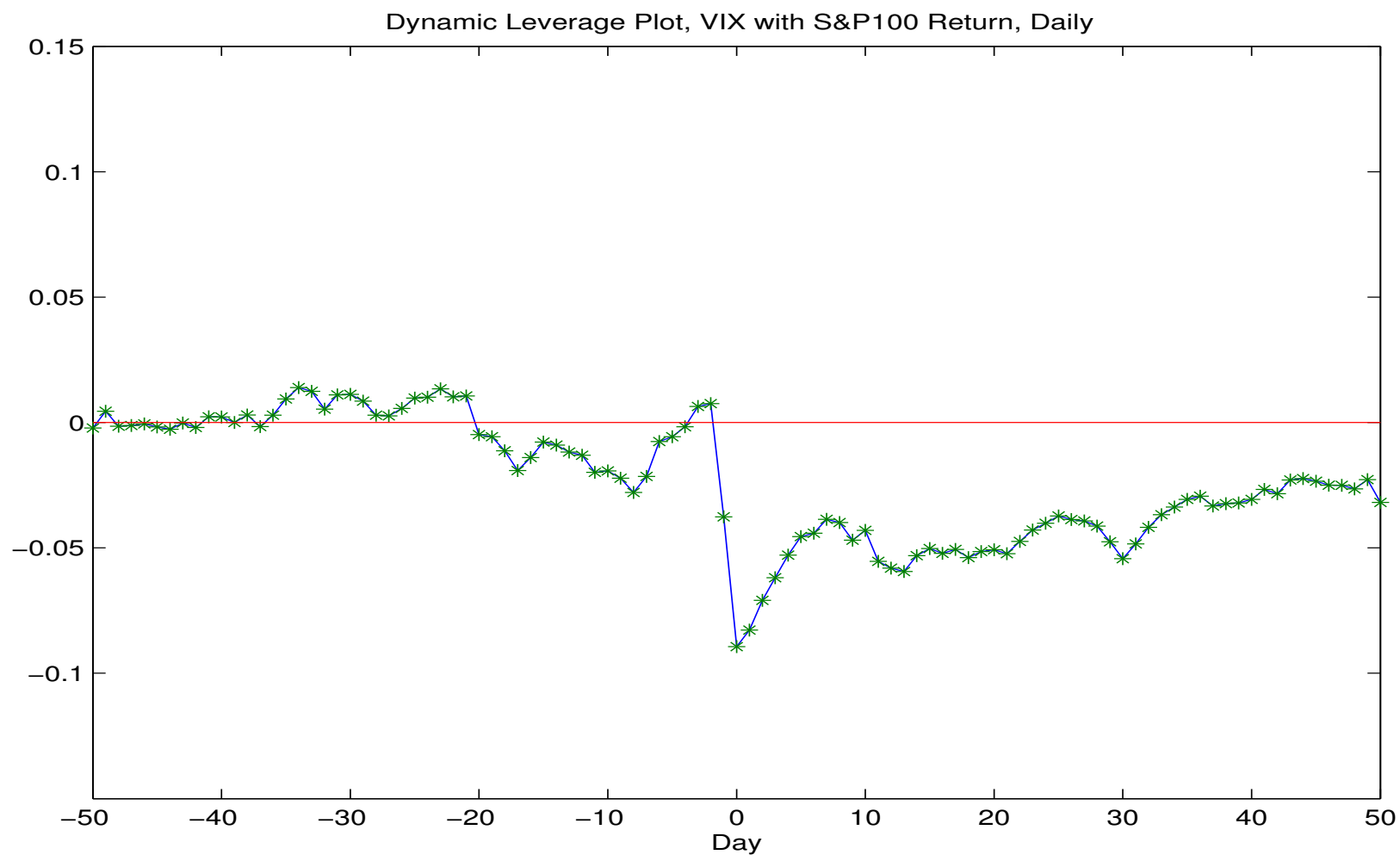

Figure 1: The figure shows shows the correlation $\operatorname{Corr}\left(\Delta p_{t}, \operatorname{vix}_{t+k}\right)$, at the daily frequency for $k=0,1, \ldots 50$ and for $k=-1,-2, \ldots,-50$. The daily log-price change is for the S\&P 100 Index and the VIX index is the daily closing value. The sample period is 1990-01-02-2004-05-21 


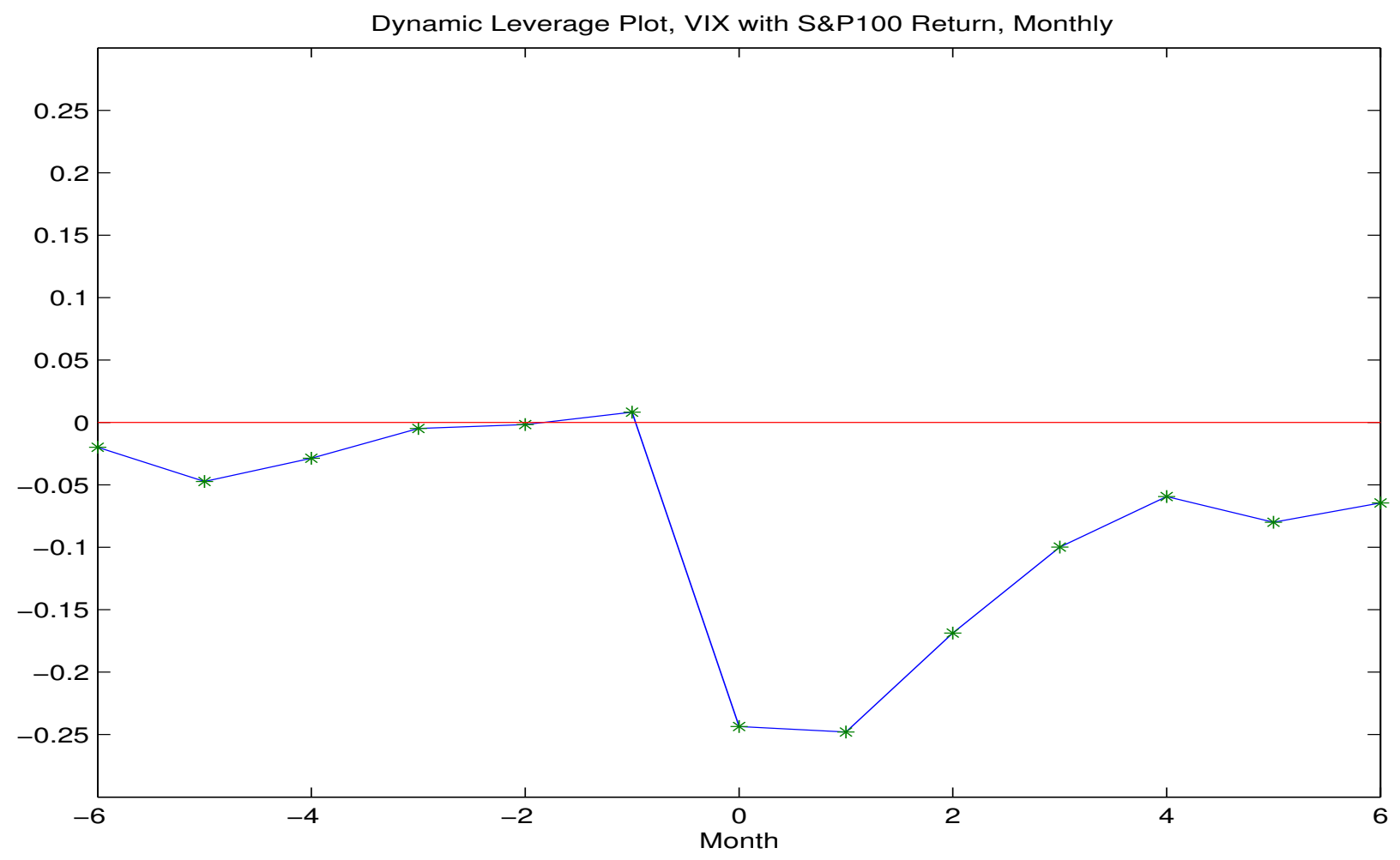

Figure 2: The figure shows shows the correlation $\left.\operatorname{Corr}\left(\overline{\Delta p}_{j}\right), \overline{v i x}_{j+l}\right)$, at the monthly frequency for $l=0,1, \ldots 5$ and for $l=-1,-2, \ldots,-5$. The monthly average log-price change $\overline{\Delta p}$ is for the S\&P 100 Index and the monthly VIX value $\overline{v i x}$ is the average of daily closing values. The sample period is 1990-01-2004-05 
Autocorrelations of Conditional Volatility, Case $A: \psi=1.50$

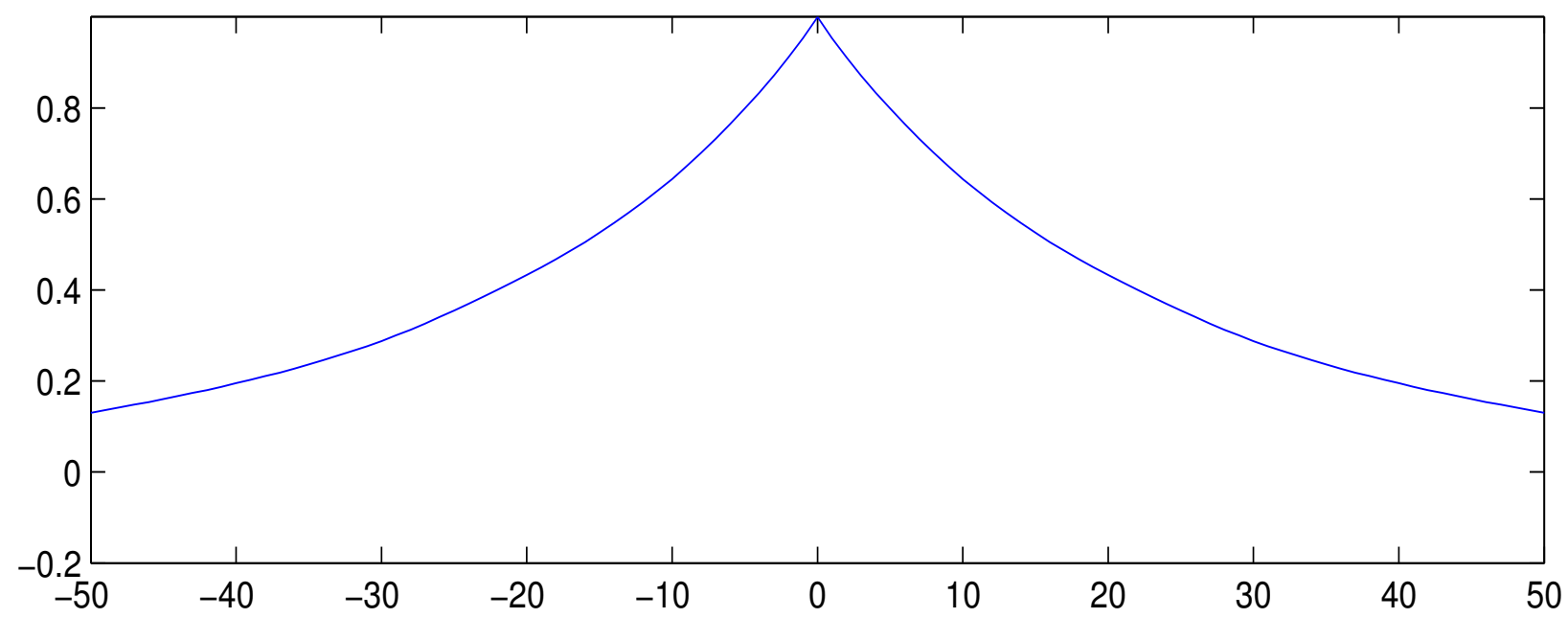

Autocorrelations of Conditional Volatility, Case B: $\psi=0.50$

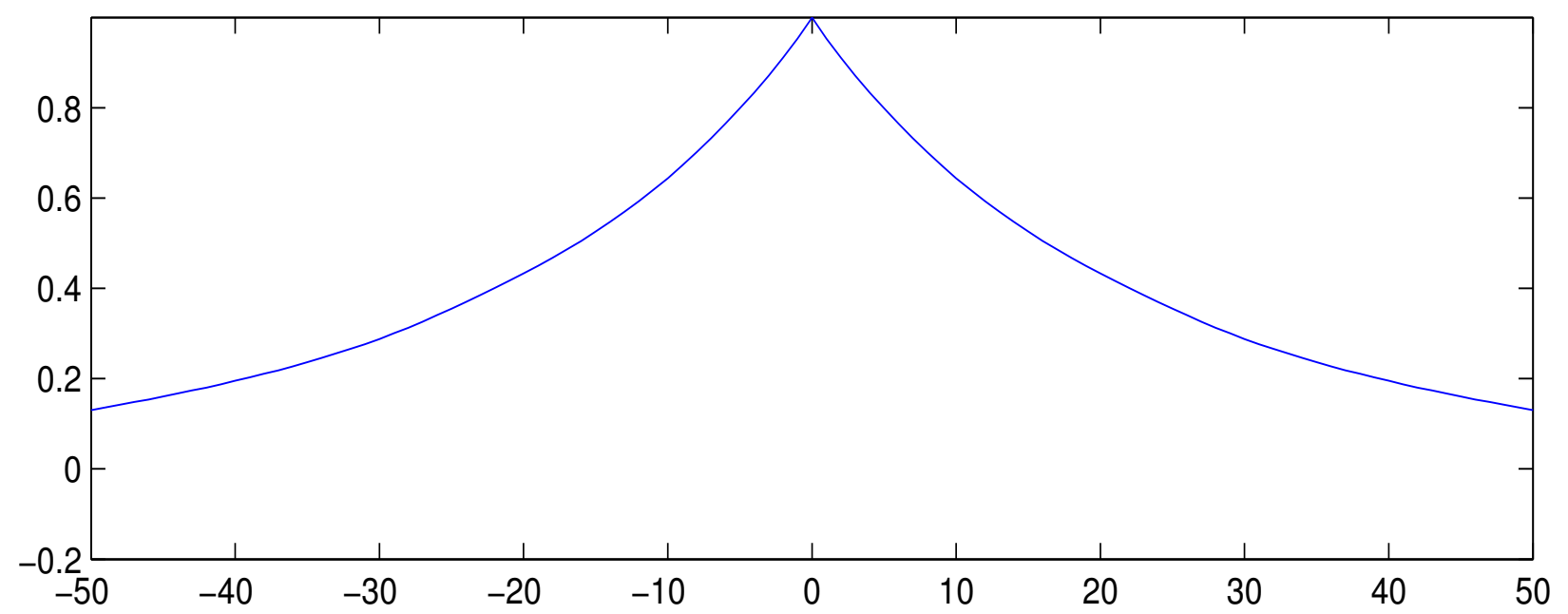

Figure 3: Each panel shows the autocorrelation function of the conditional variance process: $\operatorname{Corr}\left(\sigma_{p t}^{2}, \sigma_{p, t+j}^{2}\right), j=-50, \ldots, 50$. The top panel is computed under the parameter settings A of Table 1, where the inter-temporal elasticity of substitution is $\psi=1.50$; the bottom panel is computed under settings $\mathrm{B}$ of Table 1 , where the inter-temporal elasticity of substitution is $\psi=0.50$. Comparison of the two panels indicates that the the autocorrelation function of the conditional variance process is very insensitive to the value of $\psi$. 
Dynamic Leverage Correlations, Case A: $\psi=1.50$

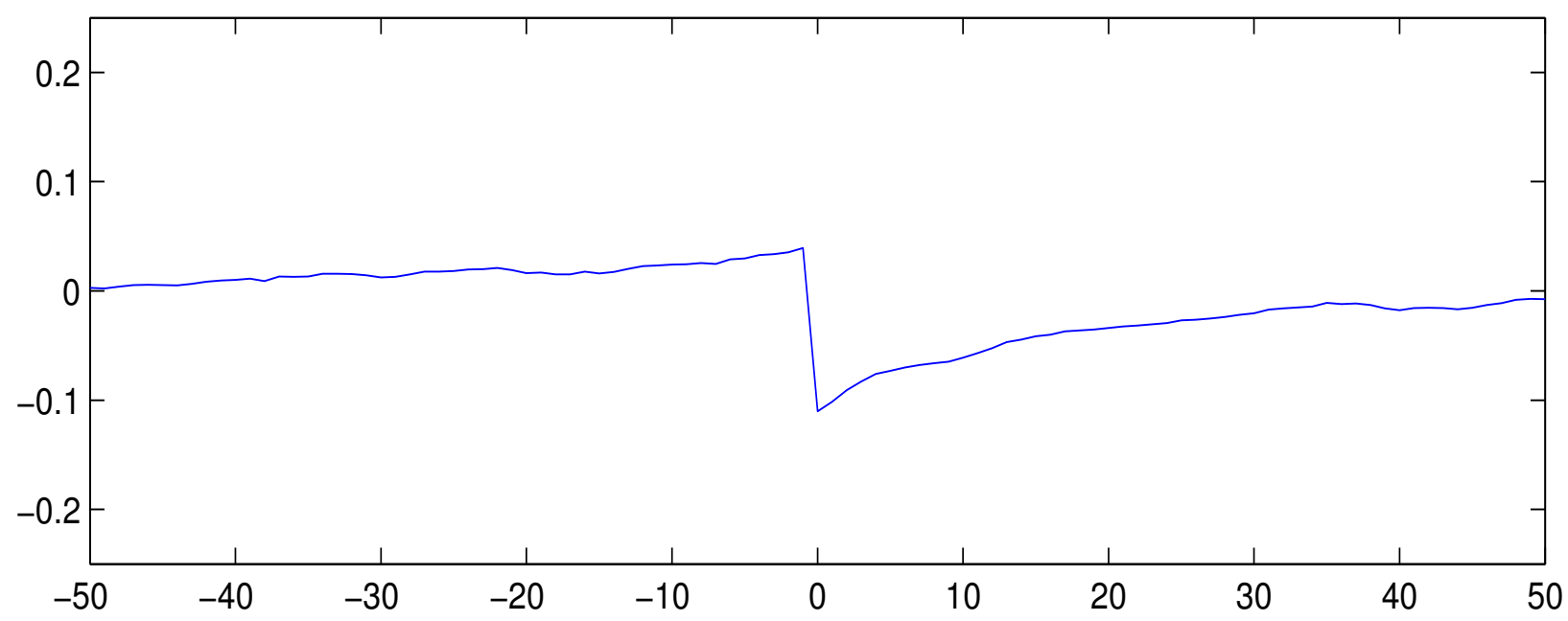

Dynamic Leverage Correlations, Case B: $\psi=0.50$

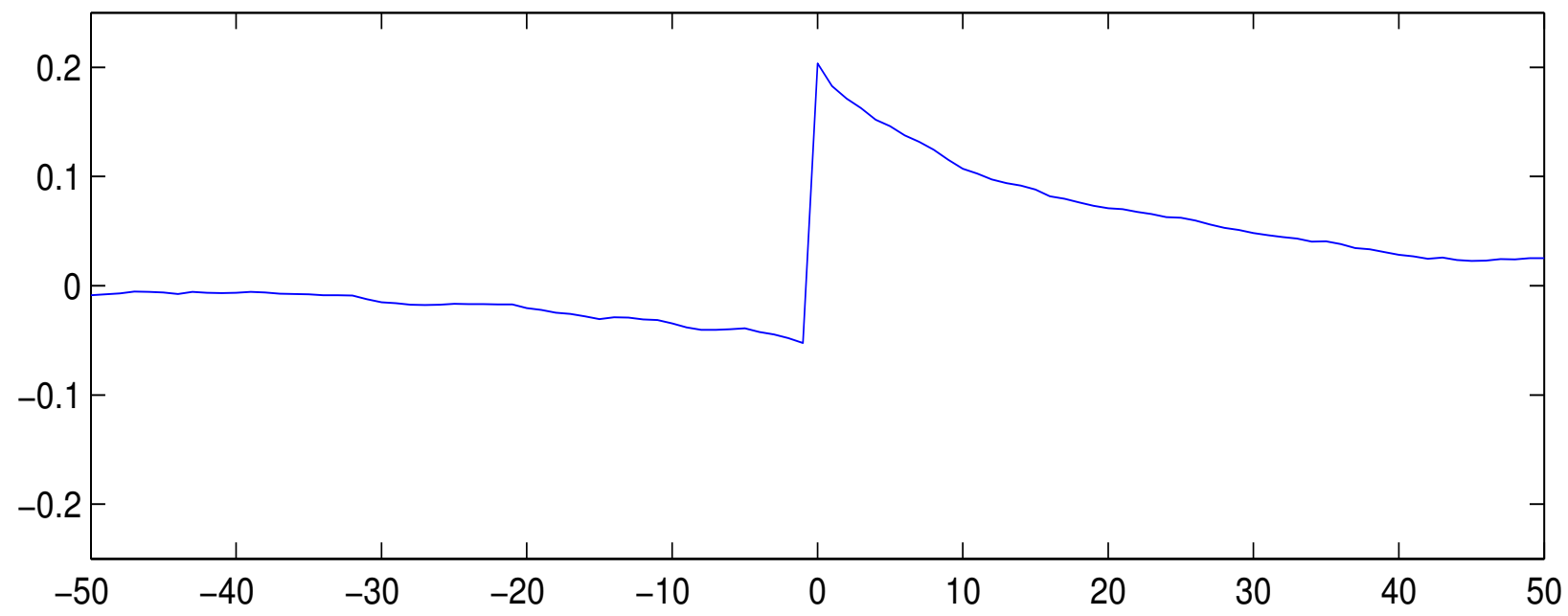

Figure 4: The right side of each panel shows the unconditional correlation of the price change with subsequent volatility, $\operatorname{Corr}\left(\Delta p_{t}, \sigma_{p, t+j}^{2}\right), j=1,2, \ldots 50$, and the left side shows the correlation of the price change with lagged volatility, $\operatorname{Corr}\left(\Delta p_{t}, \sigma_{p, t-j}^{2}\right), j=$ $1,2, \ldots 50$. The top panel pertains to the parameter settings A of Table 1 , where the inter-temporal elasticity of substitution is $\psi=1.50$; the bottom panel pertains to the parameter settings $\mathrm{B}$ of Table 1, where the inter-temporal elasticity of substitution is $\psi=0.50$. Comparison of the two panels indicates that the sign of the leverage effect depends upon the value of $\psi$ relative to unity. 


\section{References}

Adrian, Tobias, and Joshua Rosenberg (2005) "Stock Returns and Volatility: Pricing the Long-Run and Short-Run Components of Market Risk" Working Paper, Federal Reserve Bank of New York.

Alizadeh, S., M. Brandt, and F.X. Diebold (2002) "Range-Based Estimation of Stochastic Volatility Models." Journal of Finance 57, 1047-1092.

Andersen, T. G., L. Benzoni, and J. Lund (2002) "An Empirical Investigation of Continuous-time Equity Return Models." Journal of Finance 57, 1239-1284.

Andersen, T. G., T. Bollerslev, and F. X. Diebold (2002) "Parametric and Nonparametric Volatility Measurement." in L. P. Hansen and Y. Aitt-Sahalia, eds., Handbook of Financial Econometrics, North Holland, Amsterdam, forthcoming.

Andersen, T.G., T. Bollerslev, and F. Diebold (2003) "Some Like it Smooth, and Some Like it Rough: Untangling Continuous and Jump Components in Measuring, Modeling and Forecasting Asset Return Volatility." Unpublished Paper: Economics Department, Duke University.

Ang, A. and G. Bekaert, (2003), "Stock Return Predictability: Is it There?" Working Paper, Columbia University.

Bakshi, Gurdip and Nikunj Kapadia (2003) "Delta Hedged Gains and the Negative Volatility Risk Premium" Review of Financial Studies 16, 527-566.

Bansal, Ravi, A. Ronald Gallant, and George Tauchen (2004) "Rational Pessimism, Rational Exuberance, and Markets for Macro Risks," Working paper, Duke University.

Bansal, Ravi, Varoujan Khatchatrian, and Amir Yaron (2003) "Interpretable Asset Markets?" Working paper, Duke University.

Bansal, Ravi and Amir Yaron (2004) "Risks For the Long Run: A Potential Resolution of Asset Pricing Puzzles," Journal of Finance 59, 1481-1509.

Bollerslev, Tim, Robert F. Engle, and Daniel B. Nelson (1994) "ARCH Models," in Handbook of Econometrics Volume 4, Robert F. Engle and Daniel L. McFadden (eds), 2961-3038. 
Bollerslev, Tim, Julia Litvinova, and George Tauchen (2004) "Volatility Asymmetry in High Frequency Data," Working Paper, Duke University.

Barndorff-Nielsen and Shephard (2001) "Non-Gaussian Ornstein-Uhlenbeck-based models and some of their uses in financial economics (with discussion)," Journal of the Royal Statistical Society, Series B 63, 167-241.

Black, F. (1976) "Studies of Stock Price Volatility Changes," in Proceedings of the 1976 Meetings of the American Statistical Association, Business and Economics Section, 177-181.

Brandt, Michael W. and Qiang Kang (2004) "On the Relationship Between the Conditional Mean and Volatility of Stock Returns: A Latent VAR Approach," Journal of Financial Economics 72, 217-257.

Bollerslev, Tim (1986) "Generalized Autoregressive Conditional Heteroskedasticity," Journal of Econometrics 31, 307-27.

Bollerslev, Tim and Hao Zhouz (2003) "Volatility Puzzles: A Unified Framework for Gauging Return-Volatility Regressions," Working Paper, Federal Reserve Board.

Campbell, John Y. (2003) "Consumption-Based Asset Pricing", Chapter 13 in George Constantinides, Milton Harris, and Rene Stulz eds. Handbook of the Economics of Finance Vol. IB, North-Holland, Amsterdam, 803-887.

Campbell, John Y. and Hyeng Keun Koo (1997) "A Comparison of Numerical and Analytic Approximate Solutions to an Intertemporal Consumption Choice Problem," Journal of Economic Dynamics and Control 21, 273-95.

Campbell, John Y, Andrew W. Lo, and A. Craig Mackinlay (1997) The Econometrics of Financial Markets, Princeton University Press: Princeton, N.J.

Campbell, John Y. and Robert J. Shiller (1988) "The Dividend-price Ratio and Expectations of Future Dividends and Discount Factors," Review of Financial Studies 1, 195-228.

Chernov, M., A. R. Gallant, E. Ghysels, and G. Tauchen (2003) "Alternative Models for Stock Price Dynamics," Journal of Econometrics 116, 225-258. 
Christie, Andrew A (1982) "The Stochastic Behavior of Common Stock Variances: Value, Leverage and Interest Rate Effects," Journal of Financial Economics 10, 407-32.

Clark, P.(1973) "A Subordinated Stochastic Process Model with Finite Variance for Speculative Prices." Econometrica 41, 135-155.

Engle, Robert F (1982) "Autoregressive Conditional Heteroscedasticity with Estimates of the Variance of United Kingdom Inflation," Econometrica 50, 9871007.

Engle, Robert. F. and Tim Bollerslev (1986) "Modelling the Persistence of Conditional Variances," Econometric-Reviews 5, 1-50.

Engle, R. F., D. M. Lilien and R.P. Robins (1987) "Estimating Time Varying Risk Premia in the Term Structure: The ARCH-M Model", Econometrica 55, 391407.

Engle, Robert F. and Gary G. J. Lee (1999) "A Long-Run and Short-Run Component Model of Stock Return Volatility," in Cointegration, Causality, and Forecasting: A Festschrift in honour of Clive W. J. Granger. White, Halbert, eds. Oxford and New York: Oxford University Press, 475-97.

Epstein, Larry G. and Stanley E Zin (1991) "Substitution, Risk Aversion, and the Temporal Behavior of Consumption and Asset Returns: An Empirical Analysis," Journal of Political Economy 99, 263-86.

Gallant, A. R., C. T. Hsu, and G. Tauchen (1999). "Using Daily Range Data to Calibrate Volatility Diffusions and Extract the Forward Integrated Variance." The Review of Economics and Statistics 81, 617-631.

Gallant, A. R. and G. Tauchen (2002) "Simulated Score Methods and Indirect Inference for Continuous Time Models." in L. P. Hansen and Y. Aït-Sahalia, eds., Handbook of Financial Econometrics, North Holland, Amsterdam, forthcoming.

Glosten, Lawrence R., Jagannathan, Ravi, Runkle, David E. (1993) "On the Relation between the Expected Value and the Volatility of the Nominal Excess Return on Stocks" Journal of Finance 48 1779-1801 
Ghysels, Eric, Andrew Harvey, and Eric Renault (1996) "Stochastic Volatility," in Maddala, G. S.; Rao, C. R., eds. Statistical methods of finance. Handbook of Statistics series, vol. 14. Amsterdam; New York and Oxford: Elsevier, North Holland, 119-91.

Ghysels, Eric, Pedro Santa-Clara, and Rossen Valkanov (2005) "There is a RiskReturn Tradeoff After All," Journal of Financial Economics forthcoming.

Gourieroux, C., Jasiak, J., and R. Sufana (2003) "A Dynamic Model for Multivariate Stochastic Volatility." Working Paper.

Guo, Hui, Robert Savickas, Zijun Wang, and Jian Yang (2005) "Is Value Premium a Proxy for Time-Varying Investment Opportunities: Some Time Series Evidence," Working Paper, Federal Reserve Bank of St. Louis.

Guo, Hui, and Robert F. Whitelaw (2003) "Uncovering the Risk-return Relation in the Stock Market," NBER Working Paper 9927.

John R. Graham, John and Campbel R. Harvey (2001) "Volatility and Asymmetry from a Corporate Finance Perspective," Working Paper 8678, National Bureau of economic Research.

Lettau, Martin, Sydney C. Ludvigson, and Jessica A. Wachter (2004) "The Declining Equity Premium: What Role Does Macroeconomic Risk Play?" working paper, New York University.

Litvinova, Julia (2004) "Volatility Asymmetry in High Frequency Data", Ph.D. thesis, Duke University

Lundblad, Christian (2004) "Risk, Return, and Asymmetric Volatility in the LongRun: 1836-2002," Working Paper, Indiana University.

Melenberg, Bertrand and Bas J. M. Werker (2001) "The Implicit Price Of Volatility Risk: An Empirical Example," Working Paper, Tilburg University.

Melino, Angelo and Stuart Turnbull (1990) "Pricing Foreign Currency Options with Stochastic Volatility," Journal-of-Econometrics 45, 239-65.

Merton, R.C. (1973) "An Intertemporal Capital Asset Pricing Model," Econometrica $41,867-887$. 
Nelson, Daniel B. "Heteroskedasticity in Asset Returns: A New Approach," Econometrica 59, 347-370.

Pastor, L. and R. Stambaugh (2001) "The Equity Premium and Structural Breaks," Journal of Finance 56, 1207-1239.

Sarwar, Ghulam (2001) "Is Volatility Risk for the British Pound Priced in U.S. Options Markets?" Financial Review 36, 55-70.

Sarwar, Ghulam (2002) "An Empirical Investigation of the Premium for Volatility Risk in Currency Options for the British Pound," Applied Financial Economics $12,913-21$.

Scruggs, John T. (1998) "Resolving the Puzzling Intertemporal Relation between the Market Risk Premium and Conditional Market Variance: A Two-Factor Approach," Journal of Finance 53, 575-603.

Shephard, N. (2005) Stochastic Volatility: Selected Readings, Oxford University Press.

Taylor, S. J. (1982) "Financial Returns Modelled by the Product of Two Stochastic Processes - A Study of Daily Sugar Prices 1961-79." Time Series Analysis: Theory and Practice 1, 203-226, Amsterdam: North-Holland.

Taylor, S. J. (1986) Modelling Financial Time Series, Chichester: John Wiley and Sons.

Weil, Philippe (1989) "The Equity Premium Puzzle and the Risk Free Rate Puzzle," Journal of Monetary Economics 24, 401-21.

Wu, Guojun (2001) "The Determinants of Asymmetric Volatility," Review of Financial Studies 14, 837-859. 